\title{
Studies of the Mouse Foot Pad Technique for Cultivation of Mycobacterium leprae. 2. The Relationship Between Incubation Period and Generation Time
}

\author{
LOUIS LEVY AND LYDIA P. MURRAY \\ Leprosy Research Unit, Public Health Service Hospital, \\ San Francisco, California 94118, U.S.A.
}

\begin{abstract}
The results were reviewed of mouse inoculation with Mycobacterium leprae recovered from 417 skin biopsy specimens. The incubation period $(I P)$, the number of months between inoculation and the first appearance of a significant number of AFB in a monthly section, was found to be closely related to the generation time $(G)$, the average number of days per doubling. Specimens from treated patients gave larger values of $I P$ and $G$, consistent with killing of Myco. leprae during effective treatment. Forty-four specimens are described that appeared to provide inocula only marginally sufficient to infect a mouse. The results of this review confirm the validity of the use of the $I P$ and $G$ as criteria of infectivity of inocula of Myco. leprae for the mouse foot pad, and justify the practice of employing both measurements in the conduct of the technique.
\end{abstract}

\section{Introduction}

Two measurements are made in the performance of Shepard's foot pad technique (Shepard, 1960,1962). One mouse is sacrificed each month for measurement of the "incubation period" $(I P)$, the number of months that have elapsed between inoculation of the mice with a small number $\left(10^{4}\right)$ of Mycobacterium leprae and the demonstration of acid-fast bacilli (AFB) within 30 to 40 cells in histological sections of the inoculated foot pad tissues. After evidence of multiplication has been noted in a monthly section, a harvest of Myco. leprae is performed, usually from the pooled tissues of 4 foot pads. The "generation time" $(G)$ is the average number of days per doubling, calculated as if all of the inoculated bacilli multiplied at a constant rate between incubation and harvest.

Both measurements are used in determining the rate at which Myco. leprae are killed during treatment of patients with lepromatous leprosy (Collaborative Effort, 1975; Levy et al., 1972; Shepard et al., 1968, 1972a, 1972b, 1974).

* Received for publication 16 October, 1975. 
Usually, both the IP and $G$ are observed to increase at about the same rate during effective chemotherapy.

Occasionally, however, evidence of multiplication is observed in a monthly section that cannot be confirmed by harvest. And conversely, a harvest sometimes yields evidence of multiplication despite there having been no such evidence in the monthly sections obtained during one year after inoculation of the mice. In order to understand these apparently anomalous results, we have reviewed the data obtained in our laboratory during the past 8 years, and have examined the relationship between measurements of the $I P$ and $G$ for 417 skin biopsy specimens from which $M y c o$. leprae were recovered and inoculated into mice.

\section{Materials and Methods}

Since September, 1967, the Myco. leprae recovered from more than 500 skin biopsy specimens obtained from leprosy patients have been inoculated into mice in this laboratory. Of these specimens, 417 were selected for analysis because the average inoculum was at least $10^{3}$ but less than $10^{4}$ Myco. leprae/foot pad, and because data from both monthly sections and harvests of AFB from foot pad tissues were available.

Recovery of organisms from biopsy specimens, inoculation of mice and harvests of AFB from mouse foot pad tissues were accomplished by published methods (Shepard, 1960; Shepard and McRae, 1968). About half of the foot pad tissues obtained for histopathological examination were prepared by decalcification of tissue blocks cut through the entire foot (Shepard, 1962). The remaining foot pad tissues were prepared by a technique suggested by S. R. Pattyn, Prince Leopold Institute for Tropical Medicine, Antwerp, Belgium, in which the soft tissue was dissected from the metatarsals in a single piece that was fixed and subsequently sectioned.

\section{Results}

Each of 417 specimens is represented by a point in Fig. 1, which is a histogram showing the distribution of values of $G$ for all values of the $I P$ ranging from 4 to $>12$ months. Because mice were not always sacrificed earlier than 4 months after inoculation, the few specimens showing histopathological evidence of multiplication as early as the third month have been pooled with those yielding an $I P$ of four months. Mice were not sacrificed to provide material for histopathological examination later than one year after inoculation. In the 158 cases in which histopathological evidence of multiplication was not encountered within one year after inoculation, a harvest was performed from the inoculated foot pad tissues of all remaining mice to a maximum of 8 foot pads. In addition to the points representing each specimen, the median value of $G$ is shown for each value of the $I P$.

As shown in Fig. 1, there appears to be a reasonably linear relationship between the median value of $G$ in each distribution and the corresponding value of the $I P$. Because the $I P$ is a discrete rather than a continuous variable, this relationship cannot be examined by the linear regression technique. However, one may readily construct the $2 \times 2$ table shown in Table 1, which demonstrates that the 417 specimens are about evenly divided between those with $I P>8$ months and those with $I P \leqslant 8$ months. Likewise, the specimens are evenly divided between those 


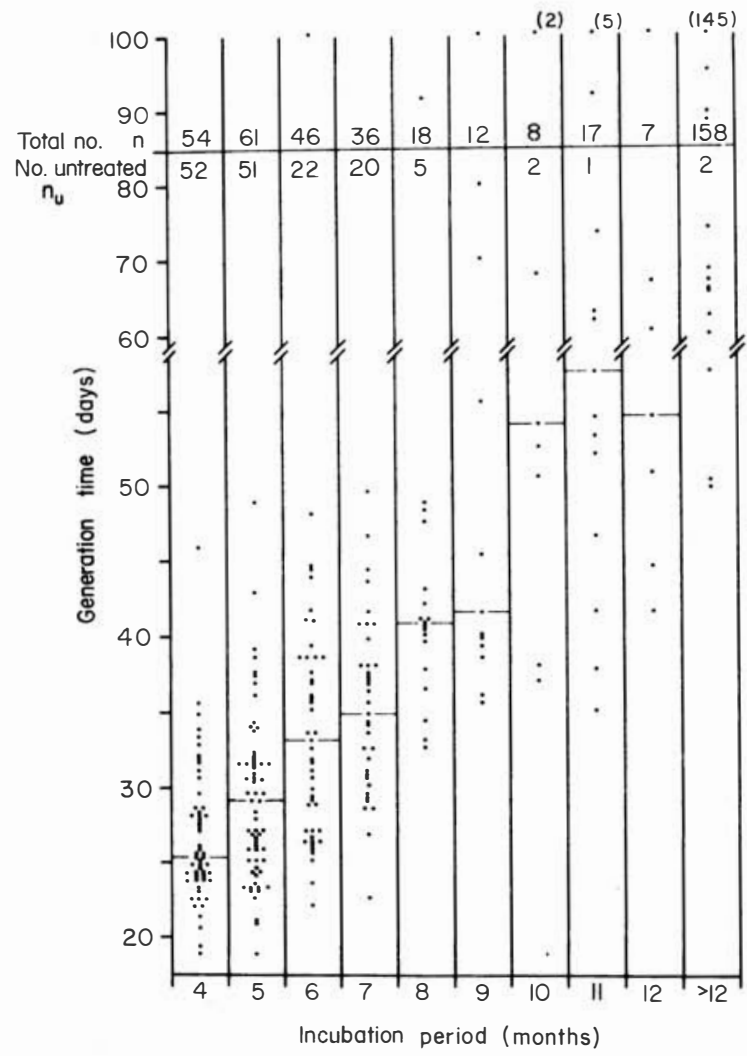

Fig. 1. Relationship of $I P$ and $G$ for 417 specimens.

with $G<40$ days and those with $G \geqslant 40$ days. About $95 \%$ of the specimens with $G<40$ days yielded an $I P \leqslant 8$ months, whereas only $14 \%$ of specimens with $G \geqslant 40$ days yielded an $I P \leqslant 8$ months. The probability that this distribution of 417 results could have occurred by chance is vanishingly small; $P$, as measured by Fisher's exact probability test (Goldstein, 1964), is about $10^{-70}$. Thus, both IP and $G$ appear to measure the same phenomenon.

Of the 417 specimens, 155 were obtained from untreated patients. The results of these specimens are not distributed uniformly across all of the values for the $I P$, but, as might be expected, represent a disproportionately large share of the specimens yielding smaller values of $I P$ and $G$. The distributions of the values of $I P$ and $G$ yielded by the specimens obtained from untreated patients are shown in Table 2. As demonstrated in the upper panel, only about $3 \%$ of the specimens from untreated patients but $75 \%$ of those obtained during treatment yielded values of the $I P>8$ months. Similarly, as the distribution in the lower panel of Table 2 shows, only about 14\% of specimens from untreated patients but $77 \%$ of those from treated patients yielded values for $G \geqslant 40$ days. The probability that either of these distributions could have been encountered by chance is negligible. 
TABLE 1

Analysis of relationship between IP and G for 417 specimens

\begin{tabular}{lcccc}
\hline \multicolumn{5}{c}{$\begin{array}{c}\text { Number of specimens } \\
G \text { (days) }\end{array}$} \\
\hline & $<40$ & $\geqslant 40$ & Total \\
IP (months) & $>8$ & 184 & 31 & 215 \\
& $>8$ & 10 & 192 & 202 \\
& Total & 194 & 223 & 417 \\
\hline
\end{tabular}

Therefore, the distributions of the values for $I P$ and $G$ obtained from treated and untreated patients are consistent with our expectations: the larger values of $I P$ and $G$ are associated with the specimens obtained from treated patients, consistent with killing of Myco. leprae during effective chemotherapy.

TABLE 2

Distributions of IP and $\mathrm{G}$ for untreated and treated patients

\begin{tabular}{|c|c|c|c|c|}
\hline & \multicolumn{4}{|c|}{ Number of specimens } \\
\hline & & Untreated & Treated & Total \\
\hline \multicolumn{5}{|l|}{ (a) } \\
\hline \multirow{3}{*}{$I P$ (months) } & $\leqslant 8$ & 150 & 65 & 215 \\
\hline & $>8$ & 5 & 197 & 202 \\
\hline & Total & 155 & 262 & 417 \\
\hline \multirow[t]{3}{*}{ (b) } & $<40$ & 135 & 60 & 194 \\
\hline & $\geqslant 40$ & 21 & 202 & 223 \\
\hline & Total & 155 & 262 & 417 \\
\hline
\end{tabular}

Of particular interest in this presentation are four categories of results summarized in Table 3, all of which may be explained by inocula containing numbers of viable organisms only marginally adequate to infect mice. Category A includes the 10 specimens shown in Fig. 1 with $I P \leqslant 12$ months and $G>60$ days but $<100$ days. All of these specimens were obtained from patients under treatment. Consistent with the large values of $G$ are the large values of $I P$ and the small numbers of AFB actually counted in each preparation and calculated as the mean value per foot pad. Portions of 6 specimens studied simultaneously in the laboratory of C. C. Shepard, Center for Disease Control, Atlanta, Georgia, or in the Leonard Wood Memorial Leprosy Research Laboratory, Cebu, Philippines, 
were found to produce multiplication of Myco. leprae in mice. The specimen yielding the median $G$ of 68.0 days gave an $I P$ of 10 months. A harvest of $M y c o$. leprae from the pooled tissues of 4 foot pads performed 355 days after inoculation produced an average of $1.86 \times 10^{5} \mathrm{AFB} /$ foot pad. Assuming a lag phase of 30 days' duration, the actual doubling time during logarithmic multiplication was 62.3 days if all 5000 of the inoculated Myco. leprae multiplied, and 18.6 days if only one infective organism per foot pad was provided by the inoculum. The smaller value is much closer to published estimates of the doubling time of 12 to 13 days (Levy, 1970; Shepard and McRae, 1965), suggesting that specimens yielding large values of $G$ are those providing proportions of Myco. leprae infective for mice no greater than 5:5000, because the minimal infective dose is about 5 infective organisms (Levy et al., 1974; Shepard and McRae, 1965).

Category B contains the 13 specimens shown in the right-hand bar of Fig. 1 to yield $I P>12$ months but $G<100$ days. Ten specimens were obtained from patients during treatment and 2 from untreated patients; the treatment status of the remaining patient is unknown. Except for the $I P>12$ months, the results of study of these specimens are much like those of Category A. Portions of 7 specimens were also studied in the Cebu laboratory; 5 yielded evidence of multiplication. The specimen yielding the median value of $G$ in this category gave, of course, $I P>12$ months. That is, 9 of the 20 mice inoculated with $4.87 \times 10^{3}$ organisms/foot pad recovered from this specimen had been sacrificed during the year following inoculation; not one demonstrated evidence of multiplication of Myco. leprae on histopathologic examination of the inoculated foot pad tissue. Because multiplication should have been apparent within one year, one or more of the 9 mice had not received the minimal infective dose. A harvest of Myco. leprae performed from a pool of 8 inoculated foot pads 364 days after inoculation yielded a mean of $2.20 \times 10^{5} \mathrm{AFB}$ per foot pad. Again assuming a 30-day lag phase and that all of the multiplication in each foot pad proceeded from a single infective organism, the actual doubling time during logarithmic multiplication may be calculated to have been 18.8 days. But it is likely that not all of the inoculated foot pads received a minimal infective dose. If only one of the 8 foot pads had actually been infected, a single infective organism doubling at a rate of once every 16 days through 21 doublings could have produced all of the organisms recovered at harvest. The single infected foot pad would have been diluted by the 7 uninfected foot pads to yield the mean number of $\mathrm{AFB} /$ foot pad found.

The eleven specimens comprising Category $\mathrm{C}$ were selected from the group of 145 specimens with $I P>12$ and $G>100$ (see Fig. 1) because the number of Myсo. leprae per foot pad calculated from the result of a harvest was greater than $10^{4}$. All of these specimens had been obtained from patients during treatment. Perhaps more informative than the average number of AFB/foot pad is the actual number of AFB counted (the fourth column in Table 3); this number was 14 for 2 specimens, 12 and 10 each for 1 specimen, 7 for 2 specimens, and 6, 4, 3, 2 and 1 each for 1 specimen. The observation of 1 to 3 organisms does not suggest that the Myco. leprae have multiplied, whereas the observation of 10 to 14 organisms almost certainly indicates that multiplication has occurred. Portions of 7 of these 11 specimens were studied in Cebu; evidence of multiplication was found for 5 of the specimens-those for which 14,12, 10 and 4 AFB were actually counted in San Francisco. One of the 2 specimens yielding 7 AFB and that yielding 3 
TABLE 3

Specimens with large values of $\mathrm{G}$

\begin{tabular}{|c|c|c|c|c|c|c|c|}
\hline \multirow[t]{3}{*}{ Category } & \multirow{3}{*}{$\begin{array}{c}\text { No. of } \\
\text { specimens }\end{array}$} & \multicolumn{4}{|c|}{ Results of study in San Francisco } & \multicolumn{2}{|c|}{ Results of study elsewhere } \\
\hline & & $\begin{array}{c}I P \\
\text { median }\end{array}$ & $\begin{array}{l}\text { No. AFB/ } \\
60 \text { fields } \\
\text { median }\end{array}$ & $\begin{array}{l}\text { No. AFB/ } \\
\text { foot pad } \\
\text { median }\end{array}$ & $\begin{array}{c}G \\
\text { median }\end{array}$ & No studied & $\begin{array}{l}\text { No. showing } \\
\text { multiplication }\end{array}$ \\
\hline & & $\begin{array}{c}\text { range } \\
\text { (months) }\end{array}$ & range & $\begin{array}{l}\text { range } \\
\left(\times 10^{3}\right)\end{array}$ & $\begin{array}{l}\text { range } \\
\text { (days) }\end{array}$ & & \\
\hline A & 10 & $\frac{11}{8-12}$ & $\frac{36}{10-110}$ & $\frac{190}{49-310}$ & $\frac{68.0}{60.7-92.1}$ & 6 & 6 \\
\hline B & 13 & $>12$ & $\frac{50}{15-183}$ & $\frac{248}{74-822}$ & $\frac{66.2}{49.7-95.2}$ & 7 & 5 \\
\hline C & 11 & $>12$ & $\frac{7}{1-14}$ & $\frac{19.0}{11.0-53.0}$ & $>100$ & 7 & 5 \\
\hline D & 10 & $\frac{11}{6-12}$ & $\frac{0}{0-7}$ & $\frac{<9.0}{<2.7-31.0}$ & $>100$ & 7 & 6 \\
\hline
\end{tabular}


organisms did not show multiplication in Cebu. Illustrative of the specimens in this category is the specimen for which 10 AFB were counted in 60 oil-immersion fields. No organisms were encountered in monthly sections during the year following inoculation of mice with $5 \times 10^{3} \mathrm{Myco}$. leprae/foot pad. A harvest performed from the pooled tissues of 8 foot pads 378 days after inoculation yielded $4.0 \times 10^{4} \mathrm{AFB} /$ foot pad with $G=126$ days. Assuming that multiplication had occurred in all of the foot pads, the doubling time during logarithmic multiplication may be shown to be 23 days, whereas the doubling time becomes 19 days if all of the enumerated organisms had been contributed by only one of the 8 foot pads. This category appears to represent an extension of Category B.

The fourth category, Category D, contains the 10 specimens with $I P \leqslant 12$ months but $G>100$ days shown at the top of Fig. 1. All but one of these specimens were obtained from patients under treatment. Seven AFB were counted in the study of the specimen with $I P=9$ months. A harvest from 8 mice performed 327 days after inoculation of $5 \times 10^{3} \mathrm{AFB} /$ foot pad yielded a mean of $3.1 \times 10^{4}$ organisms/foot pad with $G=124$ days. If all of these organisms had been contributed by one foot pad that had been infected with a single infective organism, the doubling time during logarithmic multiplication would be 17 days. Thus, Myco. leprae almost certainly multiplied in the mice inoculated with organisms from this specimen in addition to the mouse sacrificed for histopathological study 9 months after inoculation. No organisms or only one were found in harvests of 2 to 12 mice inoculated with organisms recovered from the remaining 9 specimens. Portions of 7 of these specimens were studied simultaneously in another laboratory; evidence of multiplication was found in 6 of the 7 cases.

Seven of these 44 specimens were studied with more than one harvest. The results of the harvests, shown in detail in Table 4, suggest that inoculation of mice with organisms recovered from each specimen produced irregular infection. Considering the first specimen, for example, the mouse sacrificed after 8 months to provide material for histopathological examination showed multiplication of Myco. leprae as did one or more of the 4 mice from which a harvest was made 301 days after inoculation. However, none of the 9 mice harvested later had been infected (that is, multiplication of $M y c o$. leprae had not occurred). Similarly, one may conclude that at least 2 mice inoculated with AFB from the second specimen received the minimal infective dose-the mouse yielding the $I P$ of 11 months and at least one of the mice used for harvest 379 days after inoculation, whereas none of the four mice from which a harvest was made on day 343 appears to have been infected. The organisms recovered from specimen no. 3 infected the mouse sacrificed for sections at 11 months and at least one of the 6 sacrificed for harvest at day 421, but none of the 8 mice used for harvest on day 378. The AFB from specimen nos 4, 5 and 6 appear to have infected only one mouse in each case.

The results of study of these 44 specimens have demonstrated that: (1) a harvest may yield evidence of multiplication of $M y c o$. leprae when monthly sections have not; (2) a section may show evidence of multiplication, whereas harvests do not; (3) one harvest may show evidence of multiplication, whereas one or more additional harvests from the same group of mice may not; and (4) evidence of multiplication may be found in one laboratory but not in a second when portions of the same specimens are studied simultaneously by methods shown to be entirely comparable (Collaborative Effort, unpublished data; Levy et al., 1970). Thus, a specimen yielding $G=60$ days appears likely to be one 
TABLE 4

Specimens with large values of $\mathrm{G}$ harvested more than once

\begin{tabular}{|c|c|c|c|c|c|c|c|c|}
\hline \multirow[b]{2}{*}{$\begin{array}{c}\text { No. of } \\
\text { specimen }\end{array}$} & \multirow[b]{2}{*}{ Category } & \multirow{2}{*}{$\begin{array}{l}\text { Inoculum } \\
\text { No. AFB/ } \\
\text { foot pad } \\
\left(\times 10^{3}\right)\end{array}$} & \multirow[b]{2}{*}{$\begin{array}{c}I P \\
\text { (months) }\end{array}$} & \multicolumn{5}{|c|}{ Harvest } \\
\hline & & & & $\begin{array}{l}\text { No. } \\
\text { days }\end{array}$ & $\begin{array}{l}\text { No. } \\
\text { mice }\end{array}$ & $\begin{array}{l}\text { No. AFB/ } \\
60 \text { fields }\end{array}$ & $\begin{array}{l}\text { No. AFB/ } \\
\text { foot pad } \\
\left(\times 10^{3}\right)\end{array}$ & $\begin{array}{c}G \\
\text { (days) }\end{array}$ \\
\hline 1 & A & 5.0 & 8 & $\begin{array}{l}301 \\
344 \\
384\end{array}$ & $\begin{array}{l}4 \\
4 \\
5\end{array}$ & $\begin{array}{r}10 \\
1 \\
0\end{array}$ & $\begin{array}{r}48.9 \\
9.2 \\
<4.0\end{array}$ & $\begin{aligned} & 91.5 \\
> & 100 \\
> & 100\end{aligned}$ \\
\hline 2 & A & 5.0 & 9 & $\begin{array}{l}343 \\
379\end{array}$ & $\begin{array}{l}4 \\
6\end{array}$ & $\begin{array}{r}1 \\
38\end{array}$ & $\begin{array}{r}4.5 \\
210 .\end{array}$ & $\begin{array}{r}>100 \\
70.3\end{array}$ \\
\hline 3 & A & 5.0 & 11 & $\begin{array}{l}378 \\
421\end{array}$ & $\begin{array}{l}8 \\
6\end{array}$ & $\begin{array}{r}1 \\
18\end{array}$ & $\begin{array}{l}2.9 \\
119 .\end{array}$ & $\begin{array}{r}>100 \\
92.1\end{array}$ \\
\hline 4 & B & 5.0 & $>12$ & $\begin{array}{l}370 \\
426\end{array}$ & $\begin{array}{l}8 \\
3\end{array}$ & $\begin{array}{r}29 \\
0\end{array}$ & $\begin{array}{l}161 . \\
<8.4\end{array}$ & $\begin{array}{r}73.9 \\
>100\end{array}$ \\
\hline 5 & C & 5.0 & $>12$ & $\begin{array}{l}376 \\
457\end{array}$ & $\begin{array}{l}8 \\
3\end{array}$ & $\begin{array}{r}14 \\
1\end{array}$ & $\begin{array}{r}40.1 \\
7.0\end{array}$ & $\begin{array}{l}>100 \\
>100\end{array}$ \\
\hline 6 & D & 1.1 & 10 & $\begin{array}{l}348 \\
426\end{array}$ & $\begin{array}{l}4 \\
4\end{array}$ & $\begin{array}{l}1 \\
0\end{array}$ & $\begin{array}{r}6.0 \\
<8.0\end{array}$ & $\begin{array}{l}>100 \\
>100\end{array}$ \\
\hline
\end{tabular}


containing a proportion of Myco. leprae infective for mice no larger than 5:5000. Inoculation of mice with suspensions containing smaller proportions of infective organisms appears to infect the mice irregularly.

\section{Discussion}

The purpose of this study was to examine the relationship between the 2 measurements of bacterial multiplication employed in the performance of Shepard's mouse foot pad technique for cultivation of Myco. leprae. Review of the results of the study of 417 specimens reveals a close relationship between the 2 measures in the case of 373 specimens (almost 90\%). Two hundred thirty-nine specimens yielded $I P \leqslant 12$ months and $G<60$ days, and 134 specimens yielded $I P>12$ months and $G \gg 100$ days, suggesting that the 2 measurements deal with the same phenomenon. Moreover, the fact that specimens from untreated patients account for 152 of the 239 specimens (64\%) with $I P \leqslant 12$ months and $G<60$ days and for only 1 of the 134 specimens with $I P>12$ months and $G \gg 100$ days appears to confirm the validity of these measurements as criteria of the response of patients with lepromatous leprosy to effective antimicrobial treatment.

The remaining 44 specimens were arbitrarily divided into four categories -10 with $I P \leqslant 12$ months and $G>60$ days but $<100$ days; 13 with $I P>12$ months and $G<100$ days; 11 with $I P>12$ months and $G>100$ days but with harvests yielding $>10^{4} \mathrm{AFB} /$ foot pad; and 10 with $I P \leqslant 12$ months and $G>100$ days. Of the 44 specimens, only 3 were obtained from previously untreated patients. The 41 specimens obtained from patients during treatment represent $14 \%$ of the total number of specimens obtained during treatment. Nine treatment regimens are represented; these 41 specimens accounted for 6 to $21 \%$ of the specimens in each regimen, but were not significantly segregated in any one regimen. There was perhaps a relationship between regimen and the duration of treatment at the time these specimens were obtained.

These specimens appear to represent a group intermediate between those yielding unequivocal evidence of multiplication and those yielding no such evidence, providing inocula containing only small proportions of Myco. leprae infective for mice. When the proportion is large enough (perhaps some or all of the specimens in Category $\mathrm{A}$ ), all of the mice receive a minimal infective dose; multiplication is "slow"-i.e., $G$ is large-because more doublings are required for multiplication to reach detectable levels than when a larger proportion of the inoculum consists of infective organisms. An inoculum containing only a marginally adequate proportion of infective organisms may infect mice irregularly. In fact, this has been demonstrated by Hilson in his technique of "proportional bacteriocide" (Holmes and Hilson, 1974), in which the assumption is implicit that one can always detect multiplication if it has occurred. The same assumption underlies the decision to discontinue examination of monthly sections after a year has passed; one year should be long enough for multiplication to have become apparent.

The most problematic of the 4 categories is Category D, which consists of the specimens with $I P \leqslant 12$ months and $G>100$ days. Do these results indicate multiplication, or may they represent persistence of the inoculum which has been distributed in so fortuitous a manner as to be encountered in a section cut at random through the inoculated tissue? If the latter explanation were true, one would expect to find such specimens early as well as late af ter inoculation, and 
unsupported by evidence of multiplication in a second laboratory. However, the $I P$ was 9 months or longer for 9 of the 10 specimens in this category; a second monthly section was found to show numbers of AFB in one case; evidence of multiplication was found in a second laboratory in 6 of 7 cases; and a harvest showed evidence of multiplication although $G$ was greater than 100 days in another case. Thus, the demonstration of numbers of AFB in only a single monthly section may be taken as evidence of multiplication despite $G>100$ days.

This review has provided an opportunity to assess the validity of the criteria applied to the results of mouse foot pad inoculation. Do an $I P>12$ months and $G \geqslant 100$ days separate those specimens containing Myco. leprae infective for the mouse from those that do not? If no harvests had been performed after monthly sections had failed to reveal multiplication of the organisms for 12 months, 13 of the $272(5 \%)$ specimens demonstrating multiplication would not have been so recognized. The results of a clinical drug trial would not be changed by considering these $5 \%$ of specimens to have indicated no multiplication rather than irregular multiplication from a marginally adequate inoculum. If the single infected mouse had not fortuitously been sacrificed for histopathological study in the case of the 10 specimens $(4 \%)$ yielding an $I P \leqslant 12$ months with $G \geqslant 100$ days, these specimens might have been considered not to contain infective $M y c o$. leprae; this would not have changed the results of a drug trial.

One may reasonably inquire why, if the two measures of multiplication of Myco. leprae yield essentially identical results, both should be performed. The sections are far more economical of mice and of effort, but provide only a qualitative answer. The harvest of Myco. leprae from a pool of foot pad tissues provides a more quantitative estimate of multiplication; a small value of $G$ indicates multiplication of Myco. leprae in all of the tissues in the pool from an inoculum containing greater than a minimal proportion of infective organisms. But harvests are more time-consuming and use more mice, so that one would like to know in advance of the harvest that multiplication had occurred. Therefore, the combined use of both measures appears optimal, using the results of the monthly sections to schedule the harvest. The routine developed by Shepard appears most economical-namely, to sacrifice a mouse monthly for histopathological examination, scheduling a harvest when a section shows multiplication, and considering the mice uninfected without further study if sections show no multiplication for 12 months.

\section{Acknowledgements}

This research was supported in part by the U.S. Leprosy Panel of the U.S.-Japan Cooperative Medical Science Program administered by the Geographic Medicine Branch, National Institute of Allergy and Infectious Diseases, National Institutes of Health, Bethesda, Maryland 20014, U.S.A. (Grant R22 AI 07801 and Interagency Agreement YO 1-AI 10004).

\section{References}

Collaborative Effort of the U.S. Leprosy Panel (U.S.-Japan Cooperative Medical Science Program) and the. Leonard Wood Memorial. (1975). Rifampin therapy of lepromatous leprosy. Am. J. trop. Med. Hyg. 24, 475.

Goldstein, A. (1964). Biostatistics. New York: MacMillan. 
Holmes, I.B. and Hilson, G. R. F. (1974). The rate of bactericidal action of rifampin on Mycobacterium leprae in the mouse footpad. Proc. Soc. exp. Biol. Med. 145, 1395.

Levy, L. (1970). Death of Mycobacterium leprae in mice, and the additional effect of dapsone administration. Proc. Soc. exp. Biol. Med. 135, 745.

Levy, L., Moon, N., Murray, L. P., O’Neill, S. M., Gustafson, L. E. and Evans, M. J. (1974). Studies of the mouse foot pad technic for cultivation of Mycobacterium leprae. 1. Fate of inoculated organisms. Int. J. Lepr. 42, 165.

Levy, L., Murray, L. P. and Shepard, C. C. (1970). A comparative study of mouse foot pad inoculation of skin biopsy specimens from patients with lepromatous leprosy in San Francisco and Atlanta. Int. J. Lepr. 38, 54.

Levy, L., Shepard, C. C. and Fasal, P. (1972). Clofazimine therapy of lepromatous leprosy caused by dapsone-resistant Mycobacterium leprae. Am.J. trop. Med. Hyg. 21, 315.

Shepard, C. C. (1960). The experimental disease that follows the injection of human leprosy bacilli in to foot-pads of mice. J. exp. Med. 112, 445.

Shepard, C. C. (1962). Multiplication of Mycobacterium leprae in the foot-pad of the mouse. Int. J. Lepr. 30, 291.

Shepard, C. C., Levy, L. and Fasal, P. (1968). The death of Mycobacterium leprae during treatment with 4,4'-diaminodiphenylsulfone (DDS). Am. J. trop. Med. Hyg. 17, 769.

Shepard, C. C., Levy, L. and Fasal, P. (1972a). The death rate of Mycobacterium leprae during treatment of lepromatous leprosy with acedapsone (DADDS). Am. J. trop. Med. Hyg. 21, 440.

Shepard, C. C., Levy, L. and Fasal, P. (1972b). Rapid bactericidal effect of rifampin on Mycobacterium leprae. Am. J. trop. Med. Hyg. 21, 446.

Shepard, C. C., Levy, L. and Fasal, P. (1974). Further experience with the rapid bactericidal effect of rifampin on M. leprae. Am. J. trop. Med. Hyg. 23, 1120.

Shepard, C. C. and McRae, D. H. (1965). Mycobacterium leprae in mice: minimal infectious dose, relationship between staining quality and infectivity, and effect of cortisone. $J$. Bact. 89, 365.

Shepard, C. C. and McRae, D. H. (1968). A method for counting acid-fast bacteria. Int. J. Lepr. $36,78$. 